\title{
Development of a SCAR Marker for Rapid Identification of New Kentucky Bluegrass Breeding Lines
}

\author{
Xiaojun YUAN ${ }^{1}$, Yali HE ${ }^{2 *}$, Junjie HUANG ${ }^{1}$, Wen $\mathrm{HU}^{1}$, Huanhuan $\mathrm{ZHOU}^{1}$, \\ Qiongyu $\mathrm{GAO}^{1}$, Shumin $\mathrm{ZHOU}^{1 *}$ \\ ${ }^{1}$ School of Life Science, Shanghai University, Shanghai 200444; Shanghai Key Laboratory of Bio-Energy Crops, Shanghai University, China \\ ${ }^{2}$ School of Agriculture and Biology, Shanghai Jiaotong University, Shanghai 200240, China; heyali@situ.edu.cn; zsm79@shu.edu.cn (*correspondingauthor)
}

\begin{abstract}
As a commonly used turfgrass, Kentucky bluegrass (Poa pratensis L.) (KBG) has many commercially available cultivars for production. After several years of screening, two new lines were obtained ('KBG03' and 'KBG04'), which have high tolerance to summer. The study showed that the two lines revealed similar morphological characteristics, with light green leaf color, narrow leaf blade, high plant height and light 1,000-grain weight. A total of 400 random amplified polymorphic DNA (RAPD) primers and 256 sequence-related amplified polymorphism (SRAP) primer combinations were screened among the two lines and other 4 imported commercial cultivars. The percentages of polymorphic sites were $65.5 \%$ (RAPD) and $22.6 \%$ (SRAP) respectively. By cluster analysis of RAPD and SRAP data, the dendrogram at a similarity of 0.29 gave two main clusters, of which one group had 4 commercial cultivars, and the other had the two new breeding lines. Furthermore, one specific band of 'KBG04' was successfully converted into a dominant sequence characterized amplified region marker (SCAR196). Then the SCAR marker was verified by 39 KBG DNA samples, including imported varieties, domestic varieties and self-breeding lines of our laboratory, and it exhibited high consistency with the original RAPD polymorphic amplification. The results showed that the SCAR marker can be used to distinguish the new line 'KBG04' from numerous KBG germplasms, which would be useful for cultivar identification and property rights protection in the future.
\end{abstract}

Keywords: cultivar identification, Poa pratensis, RAPD marker, SCAR marker, SRAP marker

\section{Introduction}

Kentucky bluegrass (Poa pratensis L.) (KBG) is a cool-season, attractive truf grass widely used on home lawns, golf courses and athletic fields throughout temperate regions of the world (Beard, 1973). Due to its allopolyploid origin, a complex series of polyploidy and aneuploidy exist among KBG (Huff, 2003), whereas chromosome numbers range from 24 to 124 (Love and Love, 1975). KBG produces seed both asexually (apomixis) and sexually. As to the level of apomixis, different KBG genotypes vary considerably (Meyer, 1982). Ecotype selection and intraspecific hybridization have been demonstrated as successful breeding methods for developing cultivars for the commercial turfmarket.

Compared to the U.S., China started late on KBG breeding. Therefore, no KBG commercial cultivars have occupied Chinese market, and turf seeds mainly relied on imports: 'Award', 'Nassau', 'Midnight', 'Evergreen', 'Park', 'Avanlenche', 'Langara', etc. (Sun, 2002). However, with Chinese breeders' efforts, some KBG varieties, suitable for various environments, had been developed: 'Daqingshan' from Neimenggu province, 'Qinghai' from Qinghai province (Wang et al., 2010), 'Huhe' (He et al.,
2009) and 'Huhe 2' (Yuan et al. 2014) from Shanghai laboratory.

In face of a large number of KBG varieties, many domestic studies focused on the identification of traditional botanical characteristics, comparison of some physiological and biochemical characterization of stress (heat, drought, disease etc.) resistance. Due to the complex genetic relationship among the varieties, the identification of germplasms, relying just on morphological traits, is becoming more and more difficult. It is well known that the phenotypic traits are usually influenced by environmental and physiological factors and the number of the traits is so limited. As the DNA molecular markers are more reliable and precise over traditional phenotypic markers, the use of an unlimited number of molecular markers may become a powerful tool for KBG cultivars identification.

As a relatively new marker system, sequence-related amplified polymorphism (SRAP) was first demonstrated by Li and Quiros in Brassica oleracea in 2001. SRAP marker system has many merits over others, such as simplicity, reasonable throughput rate, not crop-specific, numerous co-dominant and clear highintensity bands etc. (Aneja et al., 2012). Above all, SRAP markers 
80

preferentially amplify open reading frames (ORFs) and thus the information given by SRAP markers is more in accordance with the morphological diversity of the germplasms (Ferriol et al., 2003). SRAP markers have been widely used in several crop plants for genetic diversity analysis (Comlekcioglu et al., 2010; Ferriol et al., 2003; Zhao et al., 2009), genetic linkage map construction (Yuan et al.,2008; Xue et al., 2010; Xie et al., 2011), genes tagging (Devran et al., 2011; Zhang et al., 2011) etc. There are also some reports on turfgrass research. SRAP markers are useful for estimating genetic diversity and phenetic relationships among a wide range of cool- and warm- season turfgrass species (Budak et al., 2004a). Budak et al. (2004b) also evaluated genetic diversity in 53 buffalograss germplasms using 34 SRAP primer pairs. Wang et al. (2011) assessed genetic relationships of bermudagrass (Cynodon dactylon var. dactylon) from different countries by 30 SRAP primer combinations. Huang et al. (2012) examined the genetic variation of 12 populations of Hemarthria compressa (Poaceae) using SRAP markers.

Besides the SRAP markers, many more types of molecular markers were used in turfgrass genetic diversity analysis and germplasm identification. For example, using amplified fragment length polymorphism (AFLP) markers, Talebi-Badaf et al. (2006) analyzed the genetic diversity of five grass species with five cultivars from each. Wang et al. (2010) successfully identified 32 clonal turf bermudagrass cultivars by 11 simple sequence repeat (SSR) markers. Using 14 inter-simple sequence repeat (ISSR) primers, Farsani et al. (2012) classified 27 bermudagrass (Cynodon dactylon) genotypes from different parts of Iran into six main clusters. Random amplified polymorphic DNA (RAPD) markers were used to evaluate the genetic diversity of 19 trufgrass genotypes (mainly including 16 Poa pratensis) (Fard etal.,2012).

Table 1. Source of the cultivars and lines

\begin{tabular}{|c|c|c|c|c|c|}
\hline Code $^{1}$ & Cultivars /lines & Type, Source $^{2}$ & Code $^{1}$ & Name & Type, Source $^{2}$ \\
\hline Y01 & Odyssey & Imported vartiety; Bright & Y21 & Park & Imported variety; Clover \\
\hline Y02 & Freedom ${ }^{\text {III }}$ & Imported vartiety; Bright & Y22 & Kentucky & Imported variety; Top Green \\
\hline Y03 & Everest & Imported vartiety; Bright & Y23 & Bluechip & Imported variety; Top Green \\
\hline Y04 & Arcadia & Imported vartiety; Bright & Y24 & Bedazzled & Imported variety; Top Green \\
\hline Y05 & Nuglade & Imported vartiety; Bright & Y25 & Nublue & Imported variety; Top Green \\
\hline Y06 & Award & Imported vartiety; Bright & Y26 & Euromyth & Imported variety; Top Green \\
\hline Y07 & Nassau & Imported vartiety; Bright & Y27 & Impact & Imported variety; Top Green \\
\hline Y08 & Classic & Imported vartiety; Bright & Y28 (K1) & Langara & Imported variety; Top Green \\
\hline Y09 & Blue Chip & Imported vartiety; Bright & Y29 (K6) & Avanlanche & Imported variety; Top Green \\
\hline Y10 & Kingdom & Imported vartiety; Bright & Y30 & Huhe & Domestic variety; SJTU \\
\hline Y11 & Barrister & Imported variety; Barenbrug,China & Y31 & Daqingshan & Domestic variety; GRI IMAA\&AHS \\
\hline Y12 & Baron & Imported variety; Barenbrug,China & Y32 & Heilongjiang & Domestic variety; ISF\&ER HAAS \\
\hline Y13 & Merit & Imported variety; Barenbrug,China & Y33 & KBG01 & Self-breeding line; SABS SJTU \\
\hline Y14 & Barvictor & Imported variety; Barenbrug,China & Y34 & KBG02 & Self-breeding line; SABS SJTU \\
\hline Y15 & Midnight & Imported variety; Clover & $\mathrm{Y} 35(\mathrm{~K} 5)$ & Midnight & Imported variety; Top Green \\
\hline Y16 & Midnight II & Imported variety; Clover & Y36 (K4) & KBG03 & Self-breeding line ; SABS SJTU \\
\hline Y17 & Rugby2 & Imported variety; Clover & Y37 (K3) & KBG04 & Self-breeding line; SABS SJTU \\
\hline Y18 & Abbey & Imported variety; Clover & Y38 & $\begin{array}{c}\text { Huhe2 } \\
\text { KBG03+KBG04 }\end{array}$ & $\begin{array}{c}\text { Domestic variety, Combination of self- } \\
\text { breeding lines; SABS SJTU }\end{array}$ \\
\hline Y19 & Sapphire & Imported variety; Clover & Y39 (K2) & Evergreen & Imported variety; TopGreen \\
\hline Y20 & Blue fox & Imported variety; Clover & & & \\
\hline
\end{tabular}

1 Codes begin with $\mathrm{Y}$ in front are materials for Test 2 , while $\mathrm{K}$ for Test 1

2 Imported varieties were distributed by: Bright, Beijing Bright Turf \& Forage Co., Ltd.; Barenbrug China, Beijing Barenbrug International Co., Ltd.; Clover, Beijing Clover Turf \& Forage Co., Ltd. and TopGreen, Beijing TopGreen Seed Co., Ltd. Domestic cultivars were distributed by: GRI IMAA\&AHS, Grassland Research Institute of Inner Mongolia Acadermy of Agriculture \& Animal Husbandry Science; ISF\&ER HAAS, Institute of Soil Fertilizer and Environment Resource of Heilongjiang Acadermy of Agricultural Science; SABS SJTU, School of Agriculture and Biology Science of Shanghai Jiaotong University

\section{Plantmaterial}

Two clones ('KBG03' and 'KBG04'), resistant to summer-stress, were selected from about 133 thousand initial single plants of 18 germplasms in turf trial plots. The plot in experiment was under natural and artificial stresses of spring inoculation with one Rhizoctonia Solani Kühn isolate, the casual fungus of brown patch disease, and summer water logging between March 2006 and October 2010 (Yuan et al., 2014). According to the records of selecting procedure, 'KBG03' was originated from 'Midnight' turf test plots and 'KBG04' from 'Evergreen'. Because the similar field visual quality of the two new lines, a combination of the two has been used, as a mixed population (KBG03+KBG04) registered as a new cultivar named 'Huhe 2', which was involved in the identification.

For Test 1, six KBG germplasms (K1-K6), including 'KBG03', 'KBG04', their original commercial cultivars 'Midnight' and 'Evergreen', and other two imported commercial cultivars 'Langara' and 'Evergreen', were compared morphologically and by DNA amplification polymorphism (Table 1).

Sequence characterized amplified region (SCAR) marker is
an efficient molecular marker system, reported by Paran and Michelmore in 1993. For its reliable, specific, sensitive and rapid detection characteristics, it has been widely used in many plants in identification of turfgrass germplasms was seldom reported. This study was designed to identify the important agronomic RAPD) of the new breeding lines. Then a SCAR marker was derived from the polymorphic band and tested in more KBG identification and property rights protection.

\section{Materials and methods}


For Test 2 Sequently, 39 KBG germplasms (Y1-Y39) were used to identify the polymorphic bands by the SCAR marker (Table 1). Beside the 6 biological material aforementioned, there were 27 imported commercial cultivars, 4 domestic varieties ('Huhe', 'Huhe 2 (KBG03+KBG04)', 'Daqingshan' and 'Heilongiang'), and other two self-bred lines ('KBG01' and 'KBG02'). It should be noted that Y28, Y29, Y35, Y36, Y37 and Y39 in Test 2 were the same materials designated as K1, K6, K5, $\mathrm{K} 4, \mathrm{~K} 3$ and $\mathrm{K} 2$ respectively in Test 1.

\section{Plant culture and morphological characteristics observation}

In March 2012, 1,000-grain weight of the K1-K6 materials was measured in four replications, before seeding. The seeds were sowed into plastic containers filled with horticultural medium [peat:perlite $=7: 3(\mathrm{v}: \mathrm{v})]$. The containers were $7.6 \mathrm{~cm}$ in diameter and $20 \mathrm{~cm}$ in height, with holes pierced at the bottom for drainage. The containers of grass were first kept in a greenhouse under natural conditions, for about eight months, in Shanghai, China. Plants received a monthly application of $100 \mathrm{ml}$ fullstrength Hoagland's nutrient solution (Hoagland and Arnon, 1950) to maintain adequate nutrient levels. Turf was cut every two weeks at $6 \mathrm{~cm}$ height with a hand-clipper.

In December 2012, plants were transplanted into plots of clayey loamy soil (Soil Survey Staff, 1990) on research farm of School of Agriculture and Biology, Shanghai Jiao Tong University, Shanghai, China. From each germplasm 120 plants were randomly sampled for transplanting. The individual plants were spaced at $35 \mathrm{~cm}$ distance in rows placed at $50 \mathrm{~cm}$ apart. In May 2013, matured plant characteristics were observed before and after seed harvesting. Sixty single plants (replication) were sampled randomly for the measurements of plant height, flag leaf length, flag leaf width, and the second internode length.

\section{RAPD and SRAP analysis}

The amounts of 30 flag leaves were collected from each germplasm and frozen for subsequent extraction of genomic DNA with the CTAB method (Clark, 1998).

A total of 400 RAPD primers and 256 SRAP primer combinations were used to screen polymorphisms in the 6 materials. RAPD markers were chosen according to the sequences of NAPS Unit standard primers (University of British Columbia, Canada). SRAP markers were from $\mathrm{Li}$ and Quiros (2001), Ferriol et al. (2003), Li et al. (2003) and Wang et al.
(2005) (Table 2). All the primers were synthesized by Sangon Biological Engineering Technology and Service Co. Ltd, Shanghai.

PCR reactions for RAPD and SRAP markers were performed in 10- $\mu$ l mixture volume [ 40 ng genomic DNA, 5 pmol of each primer, $100 \mu \mathrm{mol} / \mathrm{L}$ dNTPs, $1 \times$ Taq buffer, 1.5 $\mathrm{mmol} / \mathrm{L} \mathrm{MgCl}$, and 0.5 unit of Taq DNA polymerase (TaKaRa, Talien, China)]. RAPD PCR reaction was as follows: $94^{\circ} \mathrm{C}$ for $3 \mathrm{~min}$, followed by 35 cycles at $94^{\circ} \mathrm{C}$ for $10 \mathrm{~s}$, an annealing temperature depending on different primers for $40 \mathrm{~s}$ and $72{ }^{\circ} \mathrm{C}$ for $45 \mathrm{~s}$, a final extension at $72{ }^{\circ} \mathrm{C}$ for $6 \mathrm{~min}$. The amplification products were separated on $1.5 \%$ agarose gels. The SRAP PCR reaction was as follows: $94^{\circ} \mathrm{C}$ for 3 minutes, followed by the first 8 cycles at $94^{\circ} \mathrm{C}$ for $10 \mathrm{~s}, 37^{\circ} \mathrm{C}$ for $30 \mathrm{~s}$ and $72^{\circ} \mathrm{C}$ for 1 minute. Then, the annealing temperature was raised up to $48^{\circ} \mathrm{C}$ for another 35 cycles. The last cycle was run at $72^{\circ} \mathrm{C}$ for 6 minutes. The SRAP products were separated in 4\% denatured polyacrylamide gels. The DNA bands were visualized by $\mathrm{AgNO}_{3}$ solution (Bassam et al., 1991). All PCR reactions were confirmed at least twice.

\section{Cloning and sequencing the unique fragment of new lines}

The unique amplicons of new lines were converted into SCAR markers. The specific fragments were excised from $1.5 \%$ agarose gels and retrieved with the Gel Extraction Kit (DV805A, TaKaRa, Talien, China). The target bands were ligated into the pMD18-T vector (D101A, TaKaRa, Talien, China). The positive clones bearing DNA of the expected size were sequenced in both directions by Sangon Biotech (Shanghai, China).

\section{SCAR primer design and amplification}

Primers for the SCAR marker were designed using Primer Premier5.0 software. One polymorphic SCAR marker was obtained, named as SCAR196 (Forward primer sequence: 5' CCCCCTCCTCCTCTAATAGATATTG 3'; Reverse primer sequence: 5' TCCTCCCCAATATACTTAGGTGATC 3'). The conditions of the SCAR amplification was as follows: $94^{\circ} \mathrm{C}$ for 3 minutes, followed by 38 cycles at $94^{\circ} \mathrm{C}$ for $10 \mathrm{~s}, 56^{\circ} \mathrm{C}$ for 30 s and 72 ${ }^{\circ} \mathrm{C}$ for 45 sandafinal extension at $72^{\circ} \mathrm{C}$ for 6 minutes.

\section{Data analysis}

Data of examined characters were analyzed with analysis of variance using Microsoft Excel 2000 (Levine et al., 2001) and

Table 2. List of SRAP primers used in the present study

\begin{tabular}{|c|c|c|c|}
\hline Primer name & Forward primer sequence 5'-3' & Primer name & Reverse primer sequence $5^{\prime}-3^{\prime}$ \\
\hline me1 & TGAGTCCAAACCGGATA & $\mathrm{em} 1$ & GACTGCGTACGAATTAAT \\
\hline me2 & TGAGTCCAAACCGGAGC & em2 & GACTGCGTACGAATTTGC \\
\hline me3 & TGAGTCCAAACCGGAAT & em3 & GACTGCGTACGAATTGAC \\
\hline me4 & TGAGTCCAAACCGGACC & em4 & GACTGCGTACGAATTTGA \\
\hline me5 & TGAGTCCAAACCGGAAG & em5 & GACTGCGTACGAATTAAC \\
\hline me6 & TGAGTCCAAACCGGACA & em6 & GACTGCGTACGAATTGCA \\
\hline me7 & TGAGTCCAAACCGGTGC & $\mathrm{em} 7$ & GACTGCGTACGAATTCAA \\
\hline me8 & TGAGTCCAAACCGGTAG & em8 & GACTGCGTACGAATTCTG \\
\hline me9 & TGAGTCCAAACCGGCAG & em9 & GACTGCGTACGAATTTCA \\
\hline me10 & TGAGTCCAAACCGGCAT & em 10 & GACTGCGTACGAATTGAG \\
\hline me11 & TGAGTCCAAACCGGTCT & em51 & GACTGCGTACGAATTGAT \\
\hline me 52 & TGAGTCCTTTCCGGTAA & em 14 & GACTGCGTACGAATTCAG \\
\hline me 53 & TGAGTCCTTTCCGGTCC & $\mathrm{em} 18$ & GACTGCGTACGAATTCCT \\
\hline me21 & TGAGTCGTATCCGGTCT & OD3 & ССАAAACСТАAAACCAGGA \\
\hline me22 & TGAGTCGTATCCGGAGT & SA4 & TTCTTCTTCСTGGACACAAA \\
\hline me23 & TGAGTCGTATCCGGTAG & GA18 & GGCTTGAACGAGTGACTGA \\
\hline
\end{tabular}


82

Table 3. Comparison between several mature plant characteristics of different KBG materials $(\mathrm{cm})$

\begin{tabular}{lcccc}
\hline Materials & Plant height & Flag leaf length & Flag leaf width & The second internode length \\
\hline Avanlenche & $79.2 \mathrm{c}$ & $5.2 \mathrm{~b}$ & $0.38 \mathrm{c}$ & $21.1 \mathrm{a}$ \\
Evergreen & $100.9 \mathrm{a}$ & $7.7 \mathrm{a}$ & $0.47 \mathrm{a}$ & $14.2 \mathrm{c}$ \\
KBG03 & $93.5 \mathrm{~b}$ & $4.4 \mathrm{c}$ & $0.3 \mathrm{~d}$ & $22.2 \mathrm{a}$ \\
KBG04 & $91.0 \mathrm{~b}$ & $4.1 \mathrm{c}$ & $0.28 \mathrm{~d}$ & $20.5 \mathrm{a}$ \\
Langara & $63.6 \mathrm{~d}$ & $4.5 \mathrm{c}$ & $0.43 \mathrm{~b}$ & $16.6 \mathrm{~b}$ \\
Midnight & $43.6 \mathrm{e}$ & $2.6 \mathrm{~d}$ & $0.36 \mathrm{c}$ & $9.8 \mathrm{~d}$ \\
Huhe 2 & $92.3 \mathrm{~b}$ & $4.3 \mathrm{c}$ & $0.29 \mathrm{~d}$ & $21.4 \mathrm{a}$ \\
LSD & 2.55 & 0.67 & 0.04 & 1.86 \\
\hline
\end{tabular}

Different letters indicate that means differ significantly

mean separations were performed with the Fisher's protected least significance difference test at $\mathrm{P}=0.05$ (Steel and Torrie, 1980).

Genetic relationships among the six KBG genotypes (K1K6) were analyzed with the RAPD and SRAP markers. Polymorphic bands were scored as present (1) or absent (0) among the six genotypes in a binary matrix. The data were analyzed using the Numerical Taxonomy and Multivariate Analysis System (NTSYSpc) version 2.10 (Exeter Software, Setauket, NY) and dendrogram was constructed based on the unweighted pair group method (UPGMA). Simple matching coefficient was used to calculate genetic similarity among the genotypes.

\section{Results}

\section{Comparison of matured plants' morphological traits}

In different cultivation environments, the seed plumpness of the same genotype may not always be consistent. Imported cultivars were also planted and their seeds were harvested in Shanghai so that the data of their 1,000-grain weight could be more comparable with the domestic cultivars and lines.

Analysis of variance of 1,000-grain weight showed significant difference among the six genotypes (K1-K6). Averaged 1,000grain weight values and significant differences were shown in Fig. 1. The imported seeds were significantly heavier than those of the

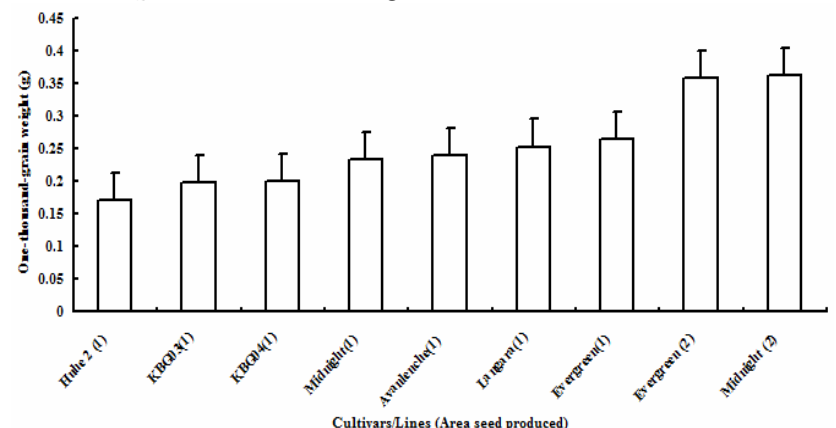

Fig. 1. 1,000-grain weight; ${ }^{1}$ Seeds were produced in Shanghai, China; ${ }^{2}$ Seeds were imported from U.S.

Bars show least significant differences at $\mathrm{p}=0.05$ (LSD0.05 $=0.042)$ same genotypes harvested in Shanghai. The 1,000-grain weight of 'Evergreen' and 'Midnight' harvested in Shanghai was only $74 \%$ and $65 \%$ of that produced in the U.S., respectively. Therefore, Shanghai is not suitable for KBG seed production. There was no significant difference among the 1,000-grain weight of these four imported commercial cultivars' seeds produced in Shanghai. Nevertheless, the 1,000-grain weight of 'KBG03', 'KBG04' and their mixed population $(\leq 0.2 \mathrm{~g})$ were all lighter than those of 'Langara' and 'Evergreen' (produced in Shanghai).

Mean phenotypic values and least significant differences of the mature plant characteristics are presented in Table 3. In all traits, significant differences among these germplasms were detected. The mean plant height, flag leaf length, flag leaf width and second internode length of the new lines ranged from 91.0$93.5 \mathrm{~cm}, 4.1-4.4 \mathrm{~cm}, 0.28-0.3 \mathrm{~cm}$, and $20.5-22.2 \mathrm{~cm}$, respectively. The plant height values of 'KBG03' and 'KBG04' were significantly higher than 'Avanlenche', 'Langara' and 'Midnight', and the flag leaf width of 'KBG04' was the narrowest of all. It showed that, within the studied germplasms, the newly selected lines 'KBG03' and 'KBG04' were very similar, with light 1,000grain weight, high plant height and narrow flag leaf width.

\section{RAPD and SRAPpolymorphism}

Among the six germplasms, 400 RAPD primers were tested for the polymorphic bands; 266 of the 400 primers $(66.5 \%)$ could amplify 1,284 clear and reproducible bands (Fig. 2). The number of fragments for each primer varied from 1 to 11 . From these 266 primers, 841 polymorphic loci were detected at a frequency of 3.2 marker bands per primer.

Using 256 primer combinations, 3,129 bands were amplified among these germplasms (Fig. 3). Each primer pair produced 1-31 clear bands, with an average of 12.2. These primer combinations generated 708 polymorphic bands (22.6\%) (2.77 marker bands per primer pair).

\section{Cluster analysis}

433 reproducible and unambiguous polymorphic bands (327 SRAPs + 106 RAPDs) were analyzed for genetic similarity coefficient (Fig. 4). The dendrogram grouped the six germplasms

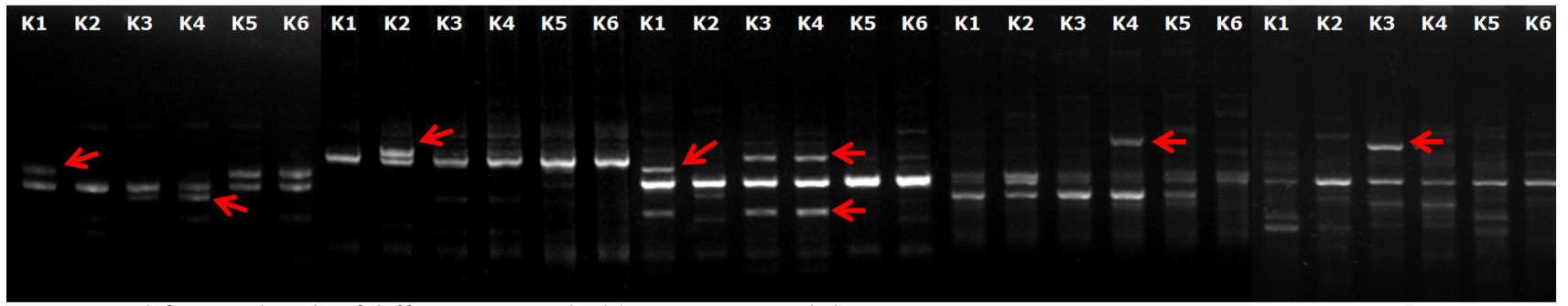

Fig. 2. Amplification bands of different Kentucky bluegrass materials by 5 primers Note: Primer 3, 82, 229, 246 and 196 (from left to right); Arrows indicate the polymorphic bands 

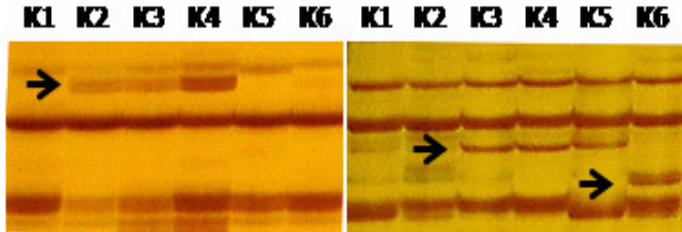

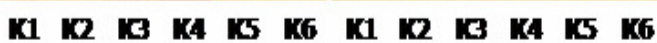

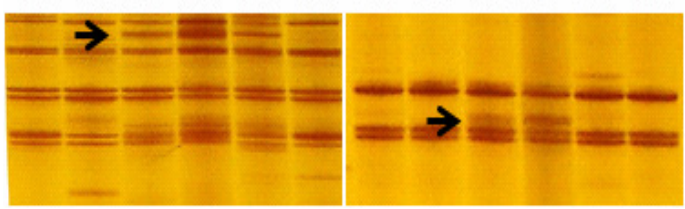

Fig. 3. Amplification bands of different Kentucky bluegrass materials by 10 SRAP primer pairs

Note: Upper line (from left to right): me21em9, melem2, me22em7, melem10 and me3em1; Lower line (from left to right): me22em9, me21em9, me2em9, me21em7, me3GA18; Arrows indicate the polymorphic bands
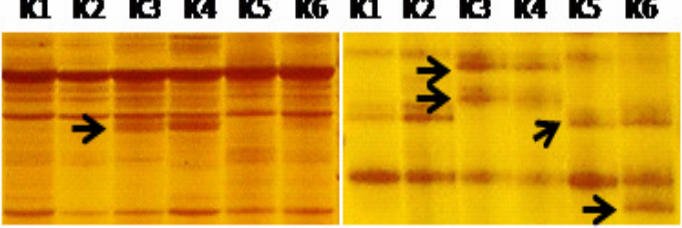

K1 IQ IC $\mathrm{KA}$ KS K6
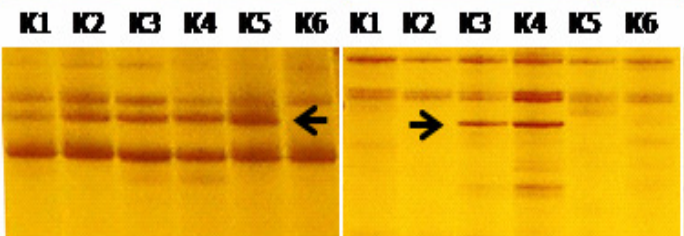

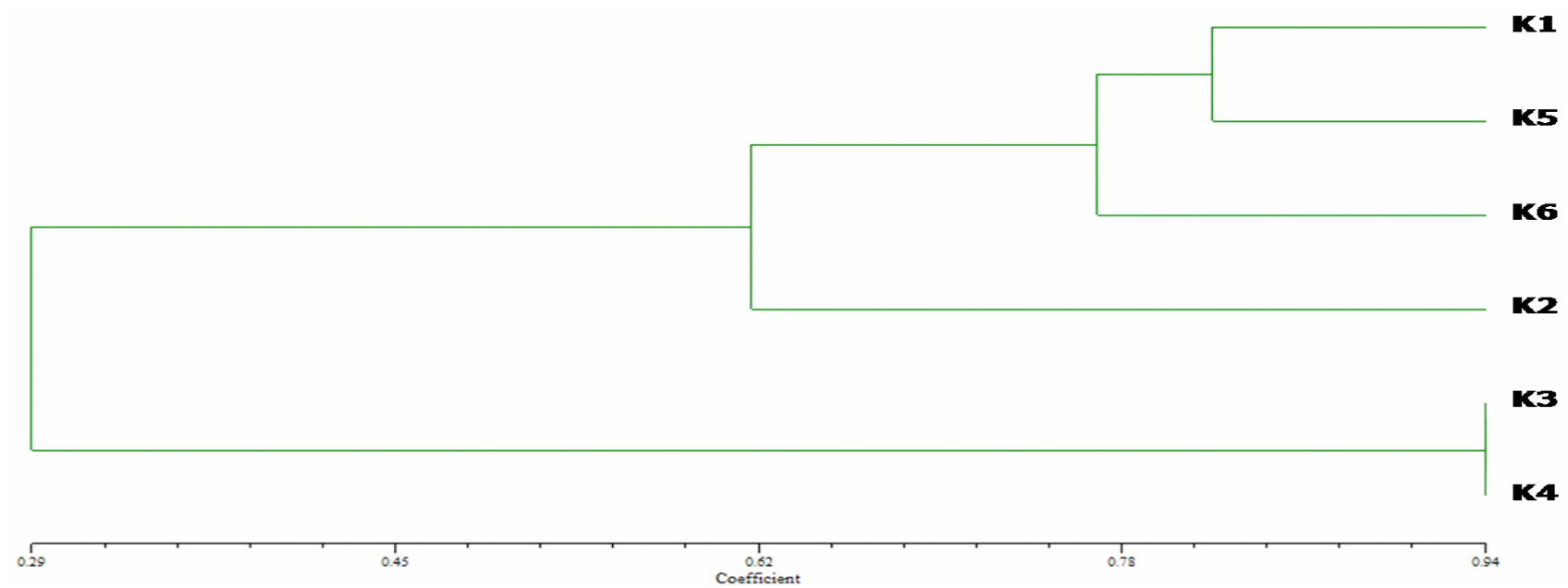

Fig. 4. UPGMA cluster analysis based on SRAP and RAPD of 6 Kentucky bluegrass genotypes

into 2 clusters at the 0.29 similarity level. The first cluster included four imported commercial cultivars, while the second cluster was comprised of the new breeding lines ('KBG03' and 'KBG04'), which were grouped at a high level of similarity.

\section{Specificity test using the SCAR marker}

The RAPD marker No.196 was converted into SCAR196. Among the six KBG materials (K1-K6), the polymorphic bands amplified by the SCAR marker were identical to those of its corresponding RAPD marker (Fig. 2, Fig. 5).

To test the specificity of the SCAR marker, genomic DNA from $39 \mathrm{KBG}$ materials (including the six materials aforementioned) were used. The polymorphic product was of $1587 \mathrm{bp}$; it appeared only in Y37 ('KBG04') and Y38 ('Huhe 2 $\left.(\mathrm{KBG} 03+\mathrm{KBG} 04)^{\prime}\right)$ and none in the others. The results showed that the specific band could be amplified by SCAR196 when the sample was 'KBG04'.

\section{Discussions}

Kentucky bluegrass is facing the serious threat of heat, high humidity or drought, diseases and insects during summer and early autumn (warm seasons) in Shanghai, China. Through a long screening progress, two newly selected lines were obtained ('KBG03' and 'KBG04') that showed better resistance to warm season stress than original cultivars ('Midnight' and 'Evergreen') under moderately low maintenance conditions, in multi-plot demonstration for several years in Shanghai (Yuan et al. 2014). At present, the mixed population of two lines has been authorized by Shanghai Crop Variety Certification Committee, named as 'Huhe 2'. Besides high stress tolerance, it has light green color, a rapid vertical growth rate and fine-leaf texture.

In this study, two newly bred lines were selected from two commercial varieties, 'Midnight' and 'Evergreen'. But

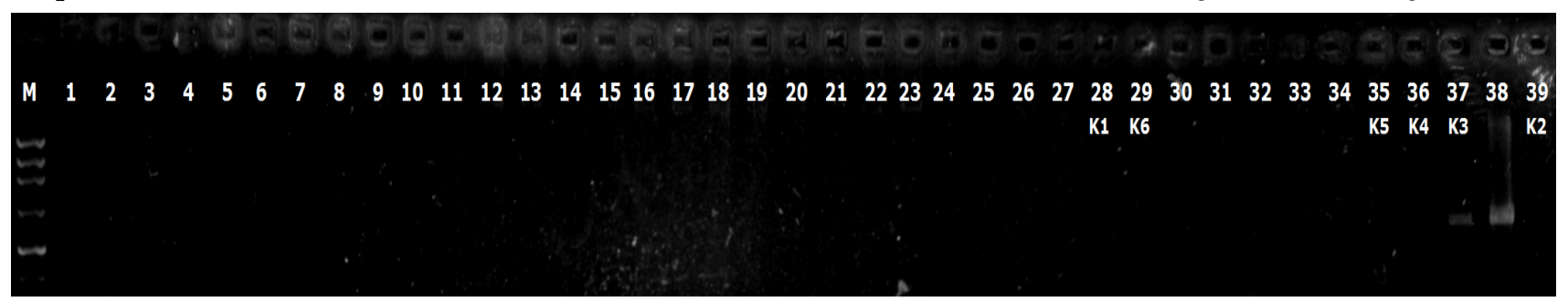

Fig. 5. Amplification of the SCAR marker SCAR196 in 39 Kentucky bluegrass materials M: 250bp DNA ladder Marker 
84

interestingly, it seemed that little comparability between the new lines and their original cultivars existed, neither in phenotype nor in molecular marker polymorphism. However, these two lines were very similar. For seed production and commercialization purposes, the commercial KBG cultivars should be highly apomictic, but hybridization in a facultative apomictic system, is still possible. These aberrant plants stand out from their parent plants, so they could be selected and reproduced asexually. Through the turf comparative trial with control cultivars, new lines might appear. Of course, it is also possible that false seeds were mixed into the varieties during the process of transportation or planting. Yet, from 39 materials collected and adaptation tested in fields during the breeding processing periods, no materials seemed similar with the new lines in phenotypes and stress tolerance. In order to accurately confirm the relationship between the KBG materials, the further study would screen the polymorphism of these germplasms (or even more) by the polymorphic markers obtained from this study.

The SRAP marker system was proved to be very useful in genetic relationship analysis among and within buffalo grasses [Buchloe dactyloides (Nutt.) Englem.] (Budal et al., 2004c). Among closely related cultivars, SRAPs performed high polymorphism (95\%), and its average discriminating power was the highest among the four systems (RAPD, ISSR, SSR and SRAP). Huang et al. (2012) also observed that the SRAP markers were more efficient than ISSR markers. The current work is the first time to detect the polymorphism among KGB germplasms by SRAP markers. As expected, more clear and reproducible bands per primer pair were generated by SRAP than RAPD. However, the percentage of polymorphic products in different studies was quite distinct, such as $72.7 \%$ in 69 C.pepo accessions with 11 primer combinations (Ferriol et al., 2003), 43.7\% in 68 Qingke accessions with 20 primer combinations (Yang et al., 2010), 82.5\% in 10 tartary buckwheat accessions with 30 primer combinations (Li et al., 2009), $71.1 \%$ in 23 mulberry accessions with 12 primer combinations (Zhao et al., 2009) etc. The present study revealed only $22.6 \%$ with 269 primer combinations in $6 \mathrm{KBG}$ genotypes. Obviously, the polymorphism frequency was related to the primer number, material number and species.

It was found that the specific band of 'KBG04' amplified by the SCAR196 (developed from the RAPD amplicon) was distinct. By a BLAST search on the sequence in the NCBI, regrettably there was no significant similarity found in nucleotide databases. Considering the characteristic of SRAP marker system, hopefully more SCAR markers would be developed from SRAP bands. Not only because that SRAPSCAR marker is an ideal tool for rapid germplasms identification, but also because more information about coding sequences could be obtained for further studies. Besides the limited unique bands of the new lines detected, low success rate of SCAR marker conversion (Horejsi, et al., 1999; Paran and Michelmore, 1993) also resulted in only one SCAR marker achieved for new line identification in this study. Actually, another SCAR marker derived from RAPD was obtained, but its amplified product was also detected in some other varieties (data not shown).

Although a SCAR marker reported here could clearly distinguish the new line 'KBG04' from others, it is hard to assure its specificity in more germplasms. So, more KBG materials would be collected from the world-wide, and then specificity tested by the SCAR marker. Meanwhile, more specific SCAR markers for the new lines, which are converted from SRAP markers, should be developed. With a combination use of more markers for cultivar identification, the result could be more accurate and reliable. Commercially, these molecular markers would also be available to KBG varieties protection.

\section{Acknowledgments}

This work was supported by the Natural Science Foundation of China (Grant No. 30972134), National Science and Technology Ministry (Grant No. 2006BAD01A19-4-6), Shanghai Municipal Agricultural Committee (Grant No. SH.AGRI.SCI (2006) No.4-5) and Shanghai Municipal Science and Technology Committee (Grant No.10391901300).

\section{References}

Aneja B, Yadav NR, Chawla V, Yadav RC (2012). Sequence-related amplified polymorphism (SRAP) molecular marker system and its applications in crop improvement. Mol Breeding 30:1635-1648.

Bassam BJ, Caetana-Anolles G, Greshoff PM (1991). Fast and sensitive silver staining of DNA in polyacrylamide gels. Anal Biochem 196:80-83.

Beard J (1973). Turfgrass: Science and culture. Prentice-Hall Inc, Englewood Cliffs, NJ, USA.

Budak H, Shearman RC, Gaussoin RE, Dweikat I (2004a). Application of sequence-related amplified polymorphism markers for characterization of turfgrass species. HortScience 39(5):955-958.

Budak H, Shearman RC, Parmaksiz I, Gaussoin RE, Riordan TP, Dweikat I (2004b). Molecular characterization of buffalograss germplasm using sequence related amplified polymorphism markers. Theor Appl Genet 108:328-334.

Budak H, Shearman C, Parmaksiz I, Dweikat I (2004c). Comparative analysis of seeded and vegetative biotype buffalograsses based on phylogenetic relationship using ISSRs, SSRs, RAPD, and SRAPs. Theor Appl Genet 109:280-288.

Clark MS (1998). Plant Molecular Biology - A Laboratory Manual. Springer-Verlag, Heidelberg.

Comlekcioglu N, Simsek O, Boncuk M, Aka-Kacar Y (2010). Genetic characterization of heat tolerant tomato (Solanum lycopersicon) genotypes by SRAP and RAPD markers. Genetics Mol Res 9(4):2263-2274.

Devran Z, Firat AF, Tor M, Mutlu N, Elekciog IH (2011). AFLP and SRAP markers linked to the $m j$ gene for root-knot nematode resistance in cucumber. Sci Agric 68(1):115-119.

Fard JR, Zamani Z, Moghaddam MRF, Kafi M (2012). Evaluation of genetic diversity among some genotypes of Kentucky bluegrass by RAPD molecular markers. Hort Environ Biotechnol 53(4):298303.

Farsani TM, Etemadi N, Sayed-Tabatabaei BE, Talebi M (2012). Assessment of genetic diversity of bermudagrass (Cynodon dactylon) using ISSR markers. Int J Mol Sci 13:383-392. 
Ferriol M, Pico B, Nuez F (2003). Genetic diversity of a germplasm collection of Cucubita pepo using SRAP and AFLP markers. Theor Appl Genet 107:271-282.

He YL, Chen J, Guo JF, Zhao ZY, Lu X (2009). Breeding of new line 'Huhe' and evaluation of germplasms of Kentucky bluegrass under artificial stressed and natural conditions in Shanghai. J Shanghai Jiaotong Univ (Agric Sci) 27(3):189-195 (in Chinese with English summary).

Hoagland CR, Arnon DI (1950). The solution-culture method for growing plants without soil. Calif Agric Exp Circ pp 347.

Horejsi T, Box JM, Staub JE (1999). Efficiency of randomly amplified polymorphic DNA to sequence characterized amplified region marker conversion and their comparative polymerase chain reaction sensitivity in cucumber.J Am Soc Hort Sci 124:128-135.

Huang LK, Zhang XQ, Xie WG, Zhang J, Cheng L, Yan HD (2012). Molecular diversity and population structure of the forage grass Hemarthria compressa (Poaceae) in south China based on SRAP markers. Genet Mol Res 11(3):2441-2450.

Huff DR (2003). Kentucky bluegrass. In: Casler MD and Duncan RR (Eds). Turfgrass biology, genetics, and breeding. John Wiley and Sons, Inc., NJ USA pp 27-38.

Levine DM, Ramsey PP, Smidt RK (2001). Applied statistics for engineers and scientists: using Microsoft Excel and MINITABLE. Prentice-Hall, Inc, Upper Asddle River, NJ.

Li G, Gao M, Yang B, Quiros CF (2003). Gene for gene alignment between the Brassica and Arabidopsis genomes by direct transcriptome mapping. Theor Appl Genet 107:168-180.

Li G, Quiros CF (2001). Sequence-related amplified polymorphism (SRAP), a new marker system based on a simple PCR reaction: its application to mapping and gene tagging in Brassica. Theor Appl Genet 103:455-461.

Li YQ, Fan XL, Shi TL, Zhang QB, Zhang ZW (2009). SRAP marker reveals genetic diversity in tartary buckwheet in china. Front Agric China 3(4):383-387.

Love A, Love D (1975). Cytotaxonomical atlas of the Artic flora. Strauss and Cramer. Leutershausen, Germany.

Meyer WA (1982). Breeding disease-resistant cool-season turfgrass cultivars for the United States. Plant Dis 66:341-344.

Paran I, Michelmore RW (1993). Development of reliable PCR-based markers linked to downy mildew resistance genes in lettuce. Theor Appl Genet 85:985-993.

Soil Survey Staff (1990). Agency for International development, United States Department of Agriculture, Soil Management Support Services. Key to soil taxonomy. Blacksburg, Va. Virginia Polytechnic Institute and State Uni pp 45-66.

Steel RGD, Torrie JH (1980). Principles and procedures of statistics ( $2^{\text {nd }}$ Edn). McGraw-Hill Book Company, New York.
Sun JX (2002). TurfScience. China Agriculture Press, Beijing.

Talebi-Badaf M, Sayed-Tabatabaei BE, Razmjoo K, Shiran B (2006). Inter and intra-species genetic diversity in perennial grassed using AFLP marker. Isfahan, J Sci Tech Agri Natur Resour 10:29-39.

Wang G, Pan JS, Li XZ, He HL, Wu AZ, Cai R (2005). Construction of a cucumber genetic linkage map with SRAP markers and location of the genes for lateral branch traits. Sci China (Ser. C) 48:213-220.

Wang LY, Bi YF, Ma YS, Shi JJ, Ji YJ (2010). Breeding of a new variety Poa pratensis L. cv. Qinghai for tolerance to low temperature. Grassl China 32(6):16-20 (in Chinese with English summary).

Wang Z, Wu YQ, Martin DL, Gao HW, Samuels T, Tan CC (2010). Identification of vegetatively propagated turf bermudagrass cultivars using simple sequence repeat markers. Crop Sci 50:2103-2111.

Wang ZY, Liao L, Yuan XJ, Guo A, Liu JX (2011). Genetic relationships of bermudagrass (Cynodon dactylon var. dactylon) from different countries revealed by sequence-related amplified polymorphism (SRAP) analysis. Afr J Biotechnol 10(75):1710617115.

Xie W, Zhang X, Huang L, Peng Y, Ma X (2011). Genetic maps of SSR and SRAP markers in diploid orchardgrass (Dactylis glomerata L.) using the pseudo-test cross strategy. Genome 54:212-221.

Xue D, Feng S, Zhao H, Jiang H, Shen B, Shi N, Lu J, Liu J, Wang H (2010). The linkage maps of Dendrobium species based on RAPD and SRAP markers.J Genetics Genomics 37:197-204.

Yang P, Liu X, Liu X, Yang W, Feng Z (2010). Diversity analysis of the developed qingke (hulless barley) cultivars representing different growing regions of the Qinghai-Tibet Plateau in China using sequence related amplified polymorphism (SRAP) markers. Afr J Biotechnol 9(50):8530-8538.

Yuan XJ, Bao ZJ, He YL (2014). Selection of new lines 'KBG03' and 'KBG04' for summer-tolerance and turf quality evaluation of the new lines with 23 other germplasms in Kentucky bluegrass. J Shanghai Jiaotong Univ (Agric Sci) 32(3):51-61 (in Chinese with English summary).

Yuan XJ, Li XZ, Pan JS, Wang G, Jiang S, Li XH, Deng SL, He HL, Si MX, Lai L, Wu AZ, Zhu LH, Cai R (2008). Genetic linkage map construction and location of QTLs for fruit-related traits in cucumber. Plant Breed 127:180-188.

Zhang F, Chen S, Chen F, Fang W, Deng Y, Chang Q, Liu P (2011). Genetic analysis and associated SRAP markers for flowering traits of chrysanthemum (Chrysanthemum morifolium). Euphytica 177:1524.

Zhao W, Fang R, Pan Y, Yang Y, Chung J, Chung M, Park Y (2009). Analysis of genetic relationship of mulberry (Morus L.) germplasm using sequence-related amplified polymorphism (SRAP) markers. Afr J Biotechnol 8(11):2604-2610. 